\title{
Simultaneous biventricular pacemaker implantation for a surgical case of aortic regurgitation with severe left ventricular dysfunction and left bundle branch block
}

\author{
Masato Nakajima, MD, ${ }^{a}$ Shigeyuki Aomi, MD, ${ }^{a}$ Naoki Matsuda, MD, ${ }^{\mathrm{b}}$ Hiroshi Kasanuki, MD, ${ }^{\mathrm{b}}$ Masahiro Endo, MD, and \\ Hiromi Kurosawa, MD, ${ }^{\text {a }}$ Tokyo, Japan
}

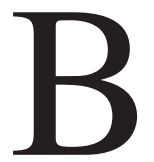

iventricular pacing is currently being explored as a means to improve cardiac function among patients with congestive heart failure. The mechanism of efficacy of this therapy is still unknown, but in patients with left bundle branch block, biventricular pacing resolves ventricular dyssynchrony and ameliorates myocardial wall function. We present a successful aortic valve replacement and biventricular pacemaker implantation for a case of aortic regurgitation with severe left ventricular dysfunction and left bundle branch block.

\section{Clinical Summary}

A 47-year-old man was referred to our hospital for detailed examination of congestive heart failure. His hemodynamic condition had deteriorated 1 month before, and he required administration of inotropic agents and ventilatory support at another hospital. He gradually recovered from cardiac shock and was transferred to our hospital. On admission, his hemodynamic condition was still unstable, and the chest $\mathrm{x}$-ray film showed cardiomegaly with a cardiothoracic ratio of $66 \%$ and massive congestion. Electrocardiography showed complete left bundle branch block with a QRS duration of 202 ms (Figure 1), whereas echocardiography revealed severe aortic regurgitation and left ventricular dilatation and dysfunction (diastolic dimension of $85 \mathrm{~mm}$, systolic dimension of $78 \mathrm{~mm}$, and fractional shortening of 0.10 ). Preoperative cardiac catheterization showed increased left ventricular enddiastolic pressure (to $18 \mathrm{~mm} \mathrm{Hg}$ ), and left ventriculography revealed a severely dilated and dysfunctional left ventricular end-diastolic volume index of $347 \mathrm{~mL} / \mathrm{m}^{2}$, a left ventricular end-systolic volume index of $237 \mathrm{~mL} / \mathrm{m}^{2}$, and an ejection fraction of $32 \%$. Aortography revealed severe aortic regurgitation (Sellers IV). The patient was scheduled for aortic valve replacement with resynchronization therapy. The patient and

From the Departments of Cardiovascular Surgery ${ }^{\mathrm{a}}$ and Cardiology, ${ }^{\mathrm{b}}$ Tokyo Women's Medical University, The Heart Institute of Japan, Tokyo, Japan.

Received for publication March 23, 2002; accepted for publication Aug 28, 2002.

Address for reprints: Masato Nakajima, MD, Department of Cardiovascular Surgery, Tokyo Women's Medical University, The Heart Institute of Japan, 8-1 Kawada-cho, Shinjyuku-ward, Tokyo, 162-8666 Japan (E-mail: masato-n@zf6.so-net.ne.jp).

J Thorac Cardiovasc Surg 2003;125:1167-9

Copyright $\odot 2003$ by The American Association for Thoracic Surgery $0022-5223 / 2003 \$ 30.00+0$

doi: $10.1067 / \mathrm{mtc} .2003 .304$ his family were informed of the risks and efficacy of this surgical treatment.

At operation, the huge heart was approached through a median sternotomy. After institution of cardiopulmonary bypass, the heart was arrested by means of antegrade and retrograde infusion of blood cardioplegic solution. The aortic valve was tricuspid, and the leaflets were thickened and shrunken. It was excised and replaced with a mechanical heart valve. After closure of the aortotomy, epicardial screw-in pacing leads were fixed on the left ventricle (base of the posterolateral wall between obtuse marginal branches), right ventricle (anteroapical portion), and right atrium (between the appendage and the sinus node). They were passed through the second intercostal space and connected to the generator (KappaDR733; Medtronic Japan Co, Ltd, Nagano, Japan) in a pocket prepared in the left subclavicular portion. The left ventricular and right ventricular leads were connected to the adapter, which makes these one lead. The patient was successfully weaned from cardiopulmonary bypass by means of an intra-aortic balloon pump with inotropic agents and biventricular pacing (DDD pacing of $80-120$ beats/min and atriobiventricular delay of $150 \mathrm{~ms}$ ). He was weaned from ventilator support on the first postoperative day, but intra-aortic balloon pump support was required for 7 days. Resynchronization therapy was continued, and paroxysmal atrial fibrillation was treated medically. Postoperative electrocardiography showed a decreased QRS duration of $110 \mathrm{~ms}$ by means of atriobiventricular pacing (Figure 2), and echocardiography showed decreased left ventricular dimension and amelioration of functional impairment (diastolic dimension of $76 \mathrm{~mm}$, systolic dimension of $62 \mathrm{~mm}$, and fractioning shortening of 0.18 ). The final pacing mode was set to DDD (lower rate of 60 beats/min with $200 \mathrm{~ms}$ of atrioventricular delay to an upper rate of 120 beats/min with $90 \mathrm{~ms}$ of atrioventricular delay) under hemodynamic analysis by using a Swan-Ganz catheter (Edwards Lifesciences, Irvine, Calif) and echocardiography. $\mathrm{He}$ was discharged from the hospital without complications and was doing well after 1 year.

\section{Comment}

As an alternative to conventional medical therapy for severe heart failure, biventricular pacing has recently been examined for its ability to improve hemodynamics by resynchronizing the ventricles in patients with intraventricular conduction delays. ${ }^{1}$ Several clinical trials for cardiac resynchronization therapy are ongoing, and recent reports suggest the possibilities of acute and long-term hemodynamic improvement. ${ }^{2-4}$

In patients with ischemic cardiomyopathy or severe left ventricular dysfunction caused by valvular heart disease, the most 


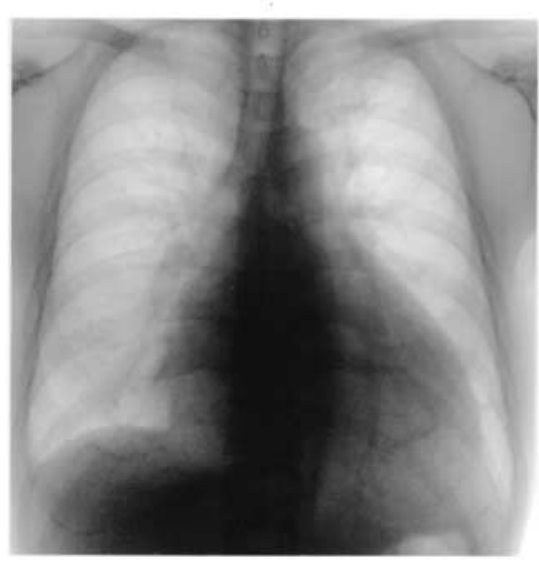

A

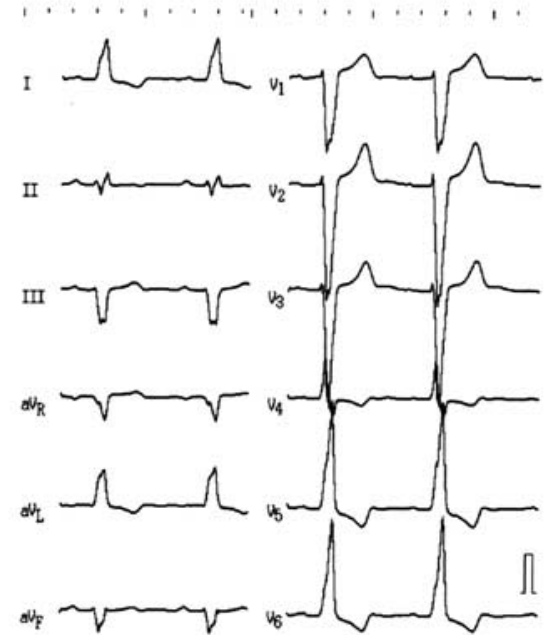

B

Figure 1. A, Preoperative chest $x$-ray film showed cardiomegaly with a cardiothoracic ratio of $66 \%$ and massive congestion. B, Electrocardiogram showed complete left bundle branch block with QRS duration of $202 \mathrm{~ms}$.

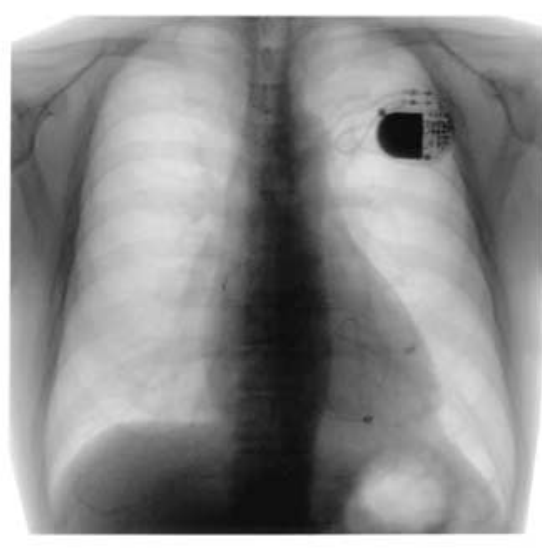

A

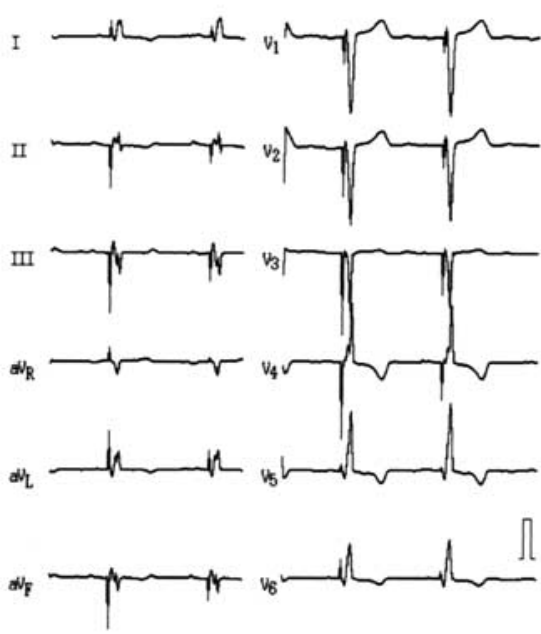

B

Figure 2. A, Postoperative chest x-ray film showed decreased cardiothoracic ratio and the pacing system implanted subclavicular portion. B, Postoperative electrocardiogram showed a decreased ORS duration of 110 ms by means of atrioventricular pacing (DDD mode).

important goal is treatment of the ischemic or valvular lesions that are causing myocardial damage. However, the risk of cardiac surgery in such patients still remains high. Therefore, we considered the combined therapy of biventricular pacing with surgical treatment as a perioperative hemodynamic assist system.
At this stage, in our limited experience, we considered that this combination therapy should be indicated in patients with severe left ventricular dysfunction caused by ischemic or valvular heart disease refractory to medical therapy and with major intraventricular conduction block. As indicated, QRS duration was more than $130 \mathrm{~ms}$. 
The most effective location for left ventricular pacing is still the subject of controversy. In our case the left ventricular lead was implanted on the midlateral portion during cardiopulmonary bypass. Ideally, the lead should be fixed on the most effective surface from which left ventricular pacing ameliorates the hemodynamic state without cardiopulmonary support, but this was difficult in a patient with a dilated and dysfunctional left ventricle. The leads were passed through the intercostal space and located in the subclavicular position. This technique might be useful for future reimplantation of the pacing lead transvenously.

\section{References}

1. Nelson GS, Berger RD, Fetics BJ, et al. Left ventricular or biventricular pacing improves cardiac function at diminished energy cost in patients with dilated cardiomyopathy and left bundle-branch block. Circulation. 2000;102:3053-9.

2. Saxon LA, Kumar UN, Marco TD. Heart failure and cardiac resynchronization therapies: US experience in the year 2000. ANE. 2000;5:188-94.

3. Auricchio A, Klein H, Tackman B, et al. Transvenous biventricular pacing for heart failure: Can the obstacles be overcome? Am J Cardiol. 1999;83:136D-42D.

4. Walker S, Levy TM, Coats AJS, et al. Bi-ventricular pacing in congestive cardiac failure. Eur Heart J. 2000;21:884-9. 